\title{
Unexpected Failures to Control Chagas Disease Vectors With Pyrethroid Spraying in Northern Argentina
}

\author{
J. M. Gurevitz ${ }^{1}$, M. S. Gaspe ${ }^{1}$, G. F. Enríquez ${ }^{1}$, C. V. Vassena ${ }^{2}$, J. A. Alvarado-Otegui ${ }^{1}$, Y. M. \\ Provecho $^{1}$, G. A Mougabure Cueto ${ }^{2}$, M. I. Picollo ${ }^{2}$, U. Kitron ${ }^{3}$, and R. E. Gürtler ${ }^{1}$ \\ ${ }^{1}$ Laboratory of Eco-Epidemiology, Department of Ecology, Genetics and Evolution, Universidad \\ de Buenos Aires, Buenos Aires, Argentina. \\ ${ }^{2}$ Centro de Investigaciones en Plagas e Insecticidas, CITEFA/CONICET, Buenos Aires, \\ Argentina. \\ ${ }^{3}$ Dept. of Environmental Studies, Emory University, Atlanta, GA 30322, USA.
}

\begin{abstract}
Effectiveness of the elimination efforts against Triatoma infestans (Klug) in South America through residual application of pyrethroid insecticides has been highly variable in the Gran Chaco region. We investigated apparent vector control failures after a standard community-wide spraying with deltamethrin SC in a rural area of northeastern Argentina encompassing 353 houses. Insecticide spraying reduced house infestation less than expected: from $49.5 \%$ at baseline to 12.3 and $6.7 \%$ at 4 and 8 mo postspraying, respectively. Persistent infestations were detected in $28.4 \%$ of houses, and numerous colonies with late-stage bugs were recorded after the interventions. Laboratory bioassays showed reduced susceptibility to pyrethroids in the local bug populations. Eleven of 14 bug populations showed reduced mortality in diagnostic dose assays (range, $35 \pm 5 \%$ to $97 \pm 8 \%$ ) whereas the remainder had $100 \%$ mortality. A fully enclosed residual bug population in a large chicken coop survived four pyrethroid sprays, including two double-dose applications, and was finally suppressed with malathion. The estimated resistance ratio of this bug population was 7.17 (range, 4.47-11.50). Our field data combined with laboratory bioassays and a residual foci experiment demonstrate that the initial failure to suppress $T$. infestans was mainly because of the unexpected occurrence of reduced susceptibility to deltamethrin in an area last treated with pyrethroid insecticides $12 \mathrm{yr}$ earlier. Our results underline the need for close monitoring of the impact of insecticide spraying to provide early warning of possible problems due to enhanced resistance or tolerance and determine appropriate responses.
\end{abstract}

\section{Keywords}

Triatoma infestans; Chagas disease; vector control; reinfestation; pyrethroid resistance

Chagas disease remains a serious public health burden in several Latin American countries. Control of the domestic vectors (Hemiptera, Triatominae) is mainly based on residual insecticide application in domestic and peridomestic structures (World Health Organization 2007). Insecticide spraying campaigns against Triatoma infestans (Klug), the main vector in the Southern Cone countries, have been highly successful in Brazil, Chile, Paraguay, and Uruguay, but were irregular and achieved moderate effects in the core of the species'

Ricardo E. Gürtler, Laboratorio de Eco-Epidemiología, Departamento de Ecología, Genética y Evolución, University of Buenos Aires, Ciudad Universitaria, 1428 Buenos Aires, Argentina. Phone/Fax: +54-11-4576-3318. gurtler@ege.fcen.uba.ar. 
distribution range in the Gran Chaco of Argentina, Bolivia and Paraguay (Gürtler et al. 2007, World Health Organization 2007).

The Southern Cone Initiative against Chagas disease, launched in 1991, envisaged the elimination of $T$. infestans by indoor residual spraying, as these populations showed susceptibility to pyrethroid insecticides, lack of sylvatic foci (except in Bolivia), and relatively low genetic variability that would have limited the emergence of pyrethroid resistance (Schmunis et al. 1996, Schofield et al. 1999). In the Gran Chaco region, however, recurrent house infestation after insecticide spraying has been associated with either: i) external foci: passive bug transport in goods or suitcases at village and regional scales, and active bug dispersal from neighboring infested villages; ii) sylvatic foci: through active and passive bug dispersal (Noireau et al. 2005), or iii) local residual foci that survived insecticide spraying, either because of insecticide resistance/tolerance or ineffective treatments, especially in peridomestic habitats (Gürtler et al. 2004, Noireau et al. 2005, Picollo et al. 2005, Cecere et al. 2006a).

The notions of insecticide resistance and tolerance both refer to the character of diminished susceptibility to an insecticide, and differ on how they arise. Resistance alludes to an increase in the character frequency in the population because of prior exposure to the insecticide (i.e., a selective pressure), whereas tolerance refers to the occurrence of this character in the population in the absence of exposure to the insecticides in question (Wilkinson 1983). In field populations, it is particularly difficult to distinguish between these two possibilities, as it is very unlikely that a full account of the history of exposure to insecticides is available. Therefore, in this study we refer to a substantially reduced susceptibility to pyrethroid insecticides (in comparison to a reference population) as 'resistance/tolerance', except where we can distinguish between the two.

As part of a multi-site research project on the sources and determinants of house reinfestation by $T$. infestans in the Gran Chaco region, we assessed the effectiveness of community-wide residual spraying with pyrethroid insecticides against $T$. infestans populations in rural northeastern Argentina and investigated the putative causes of less-thanexpected effectiveness. We here report vector control failures associated with moderate levels of pyrethroid resistance/tolerance in an area with no recent history of indoor residual spraying against $T$. infestans.

\section{Materials and Methods}

\section{Study Area}

Fieldwork was conducted in a well-defined rural area $\left(450 \mathrm{~km}^{2}\right)$ encompassing all the 353 houses of a section of the municipality of Pampa del Indio ( $\left.25^{\circ} 55^{\prime} \mathrm{S} 56^{\circ} 58^{\prime} \mathrm{W}\right)$, Chaco Province, Argentina. Vector control activities in the area had been very sparse. The last community-wide insecticide spraying campaign by vector control personnel was carried out in 1995, and a few houses had been sprayed by villagers or local hospital staff in 2006.

\section{Demographic and Entomological Surveys}

Demographic and entomological surveys were conducted at baseline, during insecticide spraying, and at 4, 8 and 12 mo postspraying. Selective insecticide resprays were performed after completing the 8 mo postspraying survey.

A sketch map of the spatial setting of all sites within each house compound was drawn, and each site was georeferenced and given an individual code in September and NovemberDecember 2007 (baseline) (Gurevitz et al. 2011). The sketch map was updated during each visit. A site was any individual structure built and/or given a defined use by householders. A 
house compound encompassed the domicile and all sites within the peridomestic area. All sites within each house were searched for triatomine bugs by timed manual collections (TMC) conducted by two skilled bug collectors using $0.2 \%$ aqueous tetramethrin (Espacial, Argentina) as a flushing-out agent. Domiciles were inspected by one person for $20 \mathrm{~min}$ while each peridomestic site was searched by another person for $15 \mathrm{~min}$. In practice, most sites were inspected thoroughly before the stipulated time, and therefore search efforts were roughly equivalent across ecotopes of different size. In several houses bugs were also collected after the stipulated search time (after-manual collections), or during insecticide applications. These additional bug collections were used as a qualitative measure of infestation. The collected triatomine bugs were transported to the field laboratory in plastic bags (labeled with unique codes for house and bug collection site), identified taxonomically and counted according to species, stage, and sex as described elsewhere (Gurevitz et al. 2011).

All houses (327 inhabited, 26 uninhabited or abandoned) and 37 public buildings were visited and inspected for bugs at baseline. Very few households refused searches for bugs at 4 mo postspraying (at three houses previously uninfested), 8 mo postspraying (at the previous three houses and another one infested both at baseline and 4 mo postspraying), and 12 mo postspraying at the same three houses and another two that were closed). The coverage of vector detection surveys (excluding public buildings) was 100, 99.1, 99.0 and $98.7 \%$ at $0,4,8$ and 12 mo postspraying (December 2008), respectively. This study was approved by Institutional Review Board $\mathrm{N}^{\circ} 00001678$ (National Institutes of Health [NIH]) in Buenos Aires, Argentina.

\section{Insecticide Application}

A community-wide insecticide spraying campaign was conducted in December 2007 immediately after the baseline survey. All sites from each house were sprayed with deltamethrin SC (K-Othrina, Bayer, Argentina) at the standard target dose $\left(25 \mathrm{mg} / \mathrm{m}^{2}\right)$ by vector control personnel using backpack manual compression sprayers (Guarany, Brazil, and Hudson, IL). Applications covered all outer and inner sides of walls, ceilings, furniture, materials susceptible of being sprayed and peridomestic structures. Only three households refused spraying, because they frequently sprayed by themselves and their houses appeared uninfested. Selective resprays with deltamethrin of all sites found infested with $T$. infestans at 4 mo (April 2008) or 8 mo (August-September 2008) postspraying were performed at the end of the 8 mo postspraying survey. To evaluate the possible higher impact of double-dose insecticide application on resistant/tolerant populations, simple- (standard) and double-dose treatments were allocated at random in peridomestic sites, while the standard dose was applied in domiciles. Preliminary bioassay results of susceptibility to the insecticide in bugs before interventions became available after the 4 mo postspraying survey.

\section{Residual Foci Experiment}

Two infested sites with large colonies of $T$. infestans at 4 mo postspraying were selected for detailed interventions and subsequent monitoring (Fig. 1). They were chosen because it was feasible to fully enclose them, and their owners expressed willingness to participate in the experiment. Site A was a small peridomestic structure $(1.5 \times 1 \times 2 \mathrm{~m}$ high) with a thatched roof and almost three of its four original mud walls standing (Fig. 1A). Formerly used as a domestic chapel in an inhabited house, it turned into a nesting and resting place for chickens and ducks. Site B was an abandoned mud hut with a tin roof $(6 \times 4 \times 3 \mathrm{~m}$ high) used by chickens and ducks to nest or rest, and occasionally by goats during the daytime (Fig. 1B); one of the outer walls had disappeared completely. 
TMC searches were performed in both sites (one person during $20 \mathrm{~min}$ ) two days before they were resprayed with pyrethroids (Supp. Fig. S1) by the same technician using the same manual compression sprayer under close supervision of a research team member in late September 2008. Four hours after spraying both sites were completely covered with cloth netting to impede in- and out-migration of triatomine bugs (day 0). One (site A) or two (site B) chickens were introduced in a cage to provide the bugs with a bloodmeal source starting at day 20; householders tended to the birds regularly. The enclosure was maintained for 61 days and was routinely checked for holes, which were fixed upon detection. During this time, knocked-down bugs found on the ground of both sites were regularly collected. Upon removal of the enclosure, TMC were conducted at the 12 mo postspraying survey. Bug searches were repeated on days 174, 237, 385, 565 and 768. Both sites were also inspected for bugs by partially dismantling $1.5 \mathrm{~m}^{2}$ of walls on days 61 and 385 . Both sites were resprayed with beta-cypermethrin (Sipertrin, Chemotecnica, Argentina) at a double dose $\left(100 \mathrm{mg} / \mathrm{m}^{2}\right)$ on days 78 and 237. Because of its persistent infestation, site B was sprayed with malathion (Onix, Cheminova, Denmark) at standard dose $\left(1 \mathrm{~g} / \mathrm{m}^{2}\right)$ on day 386 .

\section{Bioassays}

All laboratory tests for deltamethrin susceptibility were performed blindly (i.e., with no knowledge on the outcome of field interventions) on first-generation first-instar nymphs of T. infestans (aged 5-7 days and starved since hatching) whose parents had been collected at 14 study locations during the baseline survey. Treatment consisted of a topical application of $0.2 \mu \mathrm{l}$ acetone solution of deltamethrin on the dorsal abdomen of each insect (World Health Organization 1994, Picollo et al. 2005). The diagnostic dose (DD) assay determined whether the bug population was fully susceptible to deltamethrin. DD was defined as the $99 \%$ lethal dose (LD $\left.{ }_{99}\right)$ for deltamethrin of a reference susceptible bug population ( $\left.2 \mathrm{ng} / \mathrm{insect}\right)$. The DD plus a control (acetone) were assayed on each test bug population in three replicates containing at least 10 insects each. A laboratory-reared, deltamethrin-susceptible population of T. infestans and a highly deltamethrin-resistant population collected in Salta (Argentina) were used as negative (susceptible) and positive (resistant) controls, respectively. Mortality rates were recorded 24 hours after treatment. The resistance ratio (RR) to deltamethrin was assessed on first-generation insects collected at site B. First-instar nymphs were treated with deltamethrin concentrations ranging from 0.001 to $0.01 \mathrm{mg} / \mathrm{ml}$ (corresponding to 0.2 and 2 $\mathrm{ng} / \mathrm{i})$. Calculation of the $50 \%$ lethal dose $\left(\mathrm{LD}_{50}\right)$ was performed with Polo PC program (LeOra Software 1987). RR was calculated by comparison with the susceptible reference population as described elsewhere (Robertson and Preisler 1992).

\section{Data Analysis}

All results correspond only to inhabited houses because public buildings were not found infested and only one uninhabited house was ever found infested. The prevalence of infestation and colonization by $T$. infestans was calculated either for sites or house compounds. Infestation was defined by the catch of at least one live $T$. infestans nymph or adult, and colonization by the catch of at least a nymph $T$. infestans. Persistent infestation was defined as the occurrence of infestation in a given house or site both at baseline and at 4 mo postspraying. Estimates of infestation prevalence were based on the combined results of all bug collection methods unless otherwise noted. Bug abundance was computed as the number of live $T$. infestans collected in a specific site per unit of search effort by TMC. Prespraying and 4 mo postspraying bug abundances at site level were compared by means of a sign test; only sites infested according to TMC at 4 mo postspraying were considered for this test. A logistic regression model was used to assess whether persistent infestation (between baseline and 4 mo postspraying) at either site or house level (response variables) was associated with the number of days elapsed between insecticide spraying and the first 
rain postspraying, and, at site level only, with the prespraying site-specific abundance of $T$. infestans. Analyses were run on Stata 9.0 (StataCorp. 2005).

\section{Results}

\section{Community-wide Insecticide Spraying}

Residual spraying with pyrethroids reduced the house-specific prevalence of infestation with T. infestans from $46.9 \%$ at baseline to $12.0 \%$ at 4 mo postspraying in early fall and $6.7 \%$ at 8 mo postspraying in mid-winter (Fig. 2A). Of the 147 infested houses detected before initial spraying and still inhabited after spraying, $34(23.1 \%)$ remained infested at 4 mo postspraying; these houses represented $87 \%$ of the 39 infested houses detected at 4 mo postspraying (Table 1). Of 209 infested sites detected before initial spraying and still existing at 4 mo postspraying, $28(13.4 \%)$ remained infested at 4 mo postspraying, whereas 168 remained uninfested at least up to 12 mo postspraying. Of 53 sites found infested at 4 mo postspraying ( 4 of them did not exist at baseline), $64 \%$ were bug colonies with $\geq 1$ nymph.

The effectiveness of the community-wide insecticide spraying was slightly and marginally higher in sites protected from weather effects (domiciles, kitchens, and storerooms) than in more exposed sites such as chicken coops and nests $\left(\chi^{2}=7.27, \mathrm{df}=3, \mathrm{P}=0.064\right)$. The abundance of bugs determined by TMC at baseline and 4 mo postspraying was similar (onesided sign test, $\mathrm{P}=0.23$ ). A total of 2,208 and 263 live $T$. infestans was collected by TMC before initial spraying and at 4 mo postspraying (including 101 adult bugs), respectively. All bug stages were collected in all surveys, with higher representation of adults and late-stage nymphs with increasing time after initial insecticide spraying (Fig. 2B). Persistent infestations at 4 mo postspraying at house or site level were not significantly related to the time elapsed between insecticide spraying and the first rain postspraying $(P>0.64)$ by multiple logistic regression analysis; this result was not modified when controlling for the prespraying site-specific abundance of $T$. infestans. Prespraying site-specific abundance was positively and significantly associated with persistent infestation at 4 mo postspraying $(\mathrm{P}<$ 0.001 ) in the logistic regression.

\section{Selective Insecticide Spray}

After selective insecticide sprays at 8 mo postspraying, house infestation did not vary significantly between 6.7 to $5.8 \%\left(\chi^{2}=0.19, \mathrm{df}=1, \mathrm{P}=0.66\right)$ at 12 mo postspraying (early summer); $58 \%$ of the infested sites were well-protected sites (three domiciles and eight kitchens or storerooms) whereas the remainder were chicken coops. Of the 65 sites found infested at 4 or 8 mo postspraying and resprayed selectively at 8 mo postspraying, two (3.1\%) were found infested again at 12 mo postspraying including one of the experimental sites (see below). Of 17 sites first found infested at 12 mo postspraying (but not at 4 or 8 mo postspraying), seven (41\%) belonged to houses that had at least one site infested at 4 or 8 mo postspraying and had been resprayed at 8 mo postspraying. In total, 119 live $T$. infestans (including 26 adults) was collected by TMC at 12 mo postspraying. All bug stages were collected, though adults were less represented than before and fourth- or fifth-instar nymphs were relatively more frequent.

\section{Residual Foci Experiment}

The first searches by TMC (at day 61) after the initial pyrethroid spray (day 0) found no live T. infestans in site A (Fig. 3). In total, 94 bugs weres collected by knock-down, and no bug was collected thereafter at site A. In site B, bug abundance by TMC $61 \mathrm{~d}$ after the initial pyrethroid spray remained similar to preiintervention levels; 389 knocked-down bugs were collected (mostly adults) during this period (Fig. 3; Supp. Fig. S1). Partial dismantling of 
walls at day 61 provided 295 live $T$. infestans of all stages. Ninety-six days after the first double-dose pyrethroid spray, bug abundance by TMC was as high as before any insecticide spray. No bugs were detected by TMC $148 \mathrm{~d}$ after a second double-dose pyrethroid spray, but partial dismantling of walls produced 10 live bugs of various stages. No T. infestans bug was detected at this site 6 or 12 mo after spraying with malathion. In total, $793 T$. infestans were collected throughout the experiment in site B.

\section{Bioassays of Susceptibility to Insecticide}

Eleven of the 14 tested bug populations showed reduced mortality in DD assays (range, $35 \pm$ 5 to $97 \pm 8 \%$ ); the remainder had $100 \%$ mortality (Fig. 4). The lowest mortality recorded at DD assays was $35 \pm 5 \%$ whereas the reference resistant population suffered no mortality. Relative to the susceptible reference population of $T$. infestans, the estimated RR of a sample of bugs caught at site B at 12 mo postspraying (i.e., at day 61 of the residual foci experiment) was 7.17 (range, $4.47-11.50$ ) based on the $\mathrm{LD}_{50}$ of the study sample $(0.93 ; 95 \%$ CI: $0.61-1.20 \mathrm{ng} / \mathrm{i})$ with respect to the $\mathrm{LD}_{50}$ of the susceptible reference colony $(0.13 ; 95 \%$ CI: $0.12-0.15 \mathrm{ng} / \mathrm{i})$.

\section{Discussion}

Our detailed field data combined with laboratory bioassays and a residual foci experiment demonstrate that the apparent failure of pyrethroid spraying to suppress $T$. infestans populations involved an unexpected occurrence of reduced susceptibility to deltamethrin in rural communities last treated with pyrethroid insecticides $12 \mathrm{yr}$ earlier. Vector control failures detected very early at 4 mo postspraying were suggested by several pieces of evidence:

1. A moderate impact of the community-wide spraying with deltamethrin occurred in sites sheltered from adverse weather conditions that diminish the effectiveness of pyrethroids (Gürtler et al. 2004, Cecere et al. 2006b);

2. Numerous adults and fifth-instar nymphs were collected at 4 mo postspraying -hardly sufficient time for bug development to late stages from eggs (Canale and Carcavallo 1985). In contrast to our study, only $<10$ adult $T$. infestans have been found in every 60 to 100 houses sprayed with SC deltamethrin up to $12 \mathrm{mo}$ postspraying in other studies conducted in the dry Argentine Chaco (Gürtler et al. 1994, Cecere et al. 1997);

3. Persistent infestations were high and occurred in $90 \%$ of the houses infested at 4 mo postspraying;

4. A large percentage (77\%) of colonies included late-stage bugs at 4 mo postspraying and thereafter. Consistent with this pattern, pyrethroid resistance/tolerance was detected by standardized laboratory bioassays of bugs collected before and after the community-wide spraying with deltamethrin. Furthermore, a close follow-up revealed that one of the residual bug populations survived even repeated singleand double-dose pyrethroid sprays, in the absence of bug migration. Another bug population survived the initial standard dose and a second double-dose pyrethroid spray in a site fully protected from adverse weather conditions (data not shown).

Taken together, this evidence indicates that postspraying infestation comprised mainly bug colonies that survived deltamethrin treatment at local level (i.e., residual foci) and cannot be attributed to house recolonization from elsewhere (e.g., sylvatic foci, passive bug transport, or untreated external foci). 
We examined whether the persistent foci may have been the result of inadequate spray coverage or problems with the insecticide itself and found no evidence to support this hypothesis:

1. Although some bug colonies survived pyrethroid sprays, a large percentage $(86.6 \%)$ of infestations at the site level were suppressed by the first deltamethrin spray regardless of the individual spray teams that treated the sites or the time elapsed between insecticide spraying and the first rain after spraying. Moreover, $80 \%$ of sites infested at baseline and sprayed were not found infested again at least up to 12 mo postspraying, indicating that the insecticide and its application were effective;

2. Insecticide stocks were handled and stored by vector control personnel using standard procedures, and the same stock was used at each round of spraying;

3. Community-wide and selective treatments with insecticides were carried out by professional personnel acquainted with the type of buildings sprayed, and their performance was closely supervised by research team members to avert the chance of lack of or partial spray coverage;

4. Three sites remained infested after being sprayed two or more times, even when these repeat sprays were performed with particular attention in view of previous results. Therefore, it is highly unlikely that faulty procedures determined the repeated control failures observed, as illustrated by site B of the residual foci experiment.

Although the entomological follow-up does not provide unequivocal evidence of the causes for the observed control failures, the residual foci experiment does provide evidence of insecticide resistance/tolerance as the main direct cause of vector control failures, at least in some colonies. The fact that one of the experimental bug populations did not survive a second pyrethroid spray does not undermine the role of insecticide resistance/tolerance. These results show the heterogeneous impacts of insecticide sprays within the same area. In addition to the degree of resistance/tolerance of individual bug populations, there are several ecological modifiers of pyrethroid effectiveness, including variations in bug population size and stage structure (also affected by previous control measures), host availability, habitat quality, and environmental stochasticity.

The residual foci experiment also showed that TMC may not always detect infestations and measure bug population size accurately. The first three TMC within the first 174 days of the experiment produced similar bug abundances despite high bug mortality, either because indices of bug abundance lacked precision or because of a fast recovery of the bug population. After a marked decrease in bug numbers, a further timed-manual search failed to detect a low-density infestation, which was detected after partial dismantling of a wall section. These results attest to the limited sensitivity of TMC leading to under-detection of domestic and peridomestic foci, especially after insecticide spraying when bug abundance is severely reduced (Gürtler et al. 1995, Gürtler et al. 2001).

A limitation of our study is not having performed a direct assessment of the effective doses of insecticide deposited on the sprayed surfaces, nor bioassays using susceptible and putatively resistant insects exposed to the sprayed surfaces. These procedures would have provided independent measures of bug susceptibility to pyrethroids. Another limitation is the limited and uncertain number of females from which the tested first-instar nymphs came. As reported recently by Amelotti et al. (2011), susceptibility to deltamethrin may vary significantly between offspring from different females. Thus, the assay of the offspring of 
only a small number of females may give biased results on the average susceptibility to deltamethrin in a bug population.

Our results also do not enable us to clearly distinguish moderate pyrethroid resistance or pyrethroid tolerance. However, several observations support the occurrence of resistance:

1. Vector control services conducted repeated massive applications of insecticides in the area, including pyrethroids, between 10 and 40 years before our interventions;

2. Historically, pyrethroids have been highly effective in rural areas in the Argentine Chaco and other regions (Gualtieri and Baldi 1981, Paulone et al. 1988, Gürtler et al. 1994, 2007, Zerba et al. 1997, Segura 2002), suggesting that background levels of tolerance were not as strong or widespread to cause evident vector control failures;

3. Domestic application of insecticides was rather frequent ( $61 \%$ of households reported using some kind of insecticide, $51 \%$ being low-concentration insecticides, and $10 \%$ insecticides for agricultural use, including pyrethroids and carbamates) (Gurevitz et al. 2011);

4. Diminished susceptibility of $T$. infestans to pyrethroids has been reported from several areas in Argentina and Bolivia (e.g., Picollo et al. 2005, Vassena et al. 2007, Lardeux et al. 2010), and a proven focus of high pyrethroid resistance associated with repeated vector control failures has recently been detected $100 \mathrm{~km}$ from Pampa del Indio (Carvajal et al. 2012).

5. Bugs can be transported passively from distant areas where they are abundant, as demonstrated by the recent finding of a female $T$. infestans in a southern Patagonian city beyond the historical range of distribution of the species; mitochondrial DNA markers showed it most likely came from 700-1,700 km away in western or southern Argentina (Piccinali et al. 2010). Anecdotal reports indicate that some Pampa del Indio residents made regular visits to the ArgentineanBolivian border in Salta (where control failures were associated with pyrethroid resistance) to purchase low-cost clothes and sell them locally, suggesting a possible way for passive dispersal of resistant bugs.

However, there is also some evidence in favor of tolerance:

1. The study area had not experienced repeated applications of pyrethroids in recent years;

2. high levels of variability in susceptibility to deltamethrin were registered in the offspring of individual females of $T$. infestans from the southwestern Gran Chaco (Amelotti et al. 2011). As expected, the history of exposure to pyrethroid insecticides of these particular bug populations is unknown;

3. Both DD assays and pyrethroid effectiveness were highly variable in Pampa del Indio, where most bug colonies were eliminated after the first application of deltamethrin using a standard dose;

4. Our estimates of RR reached only moderate levels ranging from 4.47 to 11.50 .

But regardless of the mechanism underlying the presence of bugs with reduced susceptibility to pyrethroids, our results reveal moderate levels of pyrethroid resistance/tolerance associated with vector control failures in a rural area that apparently had no history of intense vector control actions. We believe this is a new finding which underlines the need for routine monitoring of the effectiveness of vector control actions to adjust them promptly to local characteristics or unforeseen problems. 
The last decade presented a very different scenario from the one in which the Southern Cone Initiative based its plans for the elimination of $T$. infestans using pyrethroid insecticides 20 yr ago, with multiple bug populations showing incipient levels of pyrethroid resistance/ tolerance in Argentina and Bolivia, although not always associated with vector control failures (Vassena et al. 2000, González Audino et al. 2004, Germano et al. 2010, Roca Acevedo et al. 2011), and highly resistant bug populations in areas that had experienced intense house spraying with pyrethroids. The emergence of insecticide resistance derives from the risks imposed by relying solely on one tool for pest control. In the case of Chagas disease vectors, the occurrence of pyrethroid resistance coupled with the usual difficulties in sustaining adequate rates of insecticide applications emphasize the need of incorporating other tools for integrated vector and disease control. Housing improvement, environmental and host management, and community empowerment and development, are all desirable components for a sustainable vector control strategy.

\section{Supplementary Material}

Refer to Web version on PubMed Central for supplementary material.

\section{Acknowledgments}

We thank Fundación Mundo Sano for long-term support at the study site, Jorge Nasir, the Chagas Control Program of Chaco and the National Vector Control Coordination for support in field operations; Fernando Garelli, for assistance in field work; Carla Cecere and Romina Piccinali for helpful advice. This study was supported by awards from the International Development Research Center and Tropical Disease Research (UNICEF/PNUD/WB/WHO) to R.E.G., and by National Institutes of Health/National Science Foundation Ecology of Infectious Disease program award R01 TW05836 funded by the Fogarty International Center and the National Institute of Environmental

Health Sciences to U.K., R.E.G., and Joel Cohen. This study was approved by IRB 00001678 (National Institutes of Health registered). The funders had no role in study design, data collection and analysis, decision to publish, or preparation of the manuscript. R.E.G. is member of the CONICET Researcher's Career.

\section{References}

Amelotti I, Romero N, Catalá SS, Gorla DE. Variability of the susceptibility to deltamethrin in Triatoma infestans (Hemiptera: Reduviidae). The female factor. J Med Entomol. 2011; 48:11671173. [PubMed: 22238875]

Canale, DM.; Carcavallo, RU. Triatoma infestans (Klug). In: Carcavallo, RU.; Rabinovich, JE.; Tonn, RJ., editors. Factores biológicos y ecológicos en la Enfermedad de Chagas. Buenos Aires, Argentina: Servicio Nacional de Chagas, Buenos Aires. Ministerio de Salud y Acción Social de Argentina; 1985. p. 237-250.

Carvajal G, Mougabure-Cueto G, Toloza AC. Toxicity of non-pyrethroid insecticides against Triatoma infestans (Hemiptera: Reduviidae). Mem Inst Oswaldo Cruz. 2012; 107:675-679. [PubMed: 22850959]

Cecere MC, Vazquez-Prokopec GM, Gürtler RE, Kitron U. Reinfestation sources for Chagas disease vector, Triatoma infestans Argentina. Emerg Infect Dis. 2006a; 12:1096-1102. [PubMed: 16836826]

Cecere MC, Gürtler RE, Canale D, Chuit R, Cohen JE. The role of the peridomiciliary area in the elimination of Triatoma infestans from rural Argentine communities. Rev Pan Salud Publica. 1997; $1: 273-279$

Cecere MC, Vazquez-Prokopec GM, Ceballos LA, Gurevitz JM, Zarate JE, Zaidenberg M, Kitron U, Gürtler RE. Comparative trial of effectiveness of pyrethroid insecticides against peridomestic populations of Triatoma infestans in northwestern Argentina. J Med Entomol. 2006b; 43:902-909. [PubMed: 17017227]

Germano MD, Acevedo GR, Cueto GAM, Toloza AC, Vassena CV, Picollo MI. New findings of insecticide resistance in Triatoma infestans (Heteroptera: Reduviidae) from the Gran Chaco. J Med Entomol. 2010; 47:1077-1081. [PubMed: 21175056] 
González Audino P, Vassena C, Barrios S, Zerba E, Picollo MI. Role of enhanced detoxication in a deltamethrin-resistant population of Triatoma infestans (Hemiptera, Reduviidae) from Argentina. Mem Inst Oswaldo Cruz. 2004; 99:335-339. [PubMed: 15273811]

Gualtieri JM, Baldi EM. Análisis de una experiencia piloto de control de la enfermedad de Chagas. Prensa Med Argent. 1981; 68:209-216.

Gurevitz JM, Ceballos LA, Gaspe MS, Alvarado-Otegui JA, Enríquez GF, Kitron U, Gürtler RE. Factors affecting infestation by Triatoma infestans in a rural area of the humid Chaco in Argentina: a multi-model inference approach. PLoS Negl Trop Dis. 2011; 5:e1349. [PubMed: 22028941]

Gürtler RE, Chuit R, Cecere MC, Castañera MB. Detecting domestic vectors of Chagas disease: a comparative trial of six methods in north-west Argentina. Bull World Health Organ. 1995; 73:487-494. [PubMed: 7554021]

Gürtler R, Vazquez-Prokopec GM, Ceballos LA, Lund Petersen C, Salomon OD. Comparison between two artificial shelter units and timed manual collections for detecting peridomestic Triatoma infestans (Hemiptera: Reduviidae) in rural northwestern Argentina. J Med Entomol. 2001; 28:429_ 436. [PubMed: 11372969]

Gürtler RE, Kitron U, Cecere MC, Segura EL, Cohen JE. Sustainable vector control and management of Chagas disease in the Gran Chaco, Argentina. Proc Natl Acad Sci U S A. 2007; 104:1619416199. [PubMed: 17913895]

Gürtler RE, Petersen RM, Cecere MC, Schweigmann NJ, Chuit R, Gualtieri JM, Wisnivesky-Colli C. Chagas disease in north-west Argentina: risk of domestic reinfestation by Triatoma infestans after a single community-wide application of deltamethrin. Trans R Soc Trop Med Hyg. 1994; 88:2730. [PubMed: 8153989]

Gürtler RE, Canale DM, Spillmann C, Stariolo R, Salomon OD, Blanco S, Segura EL. Effectiveness of residual spraying of peridomestic ecotopes with deltamethrin and permethrin on Triatoma infestans in rural western Argentina: a district-wide randomized trial. Bull World Health Organ. 2004; 82:196-205. [PubMed: 15112008]

Lardeux F, Depickere S, Duchon S, Chavez T. Insecticide resistance of Triatoma infestans (Hemiptera, Reduviidae) vector of Chagas disease in Bolivia. Trop Med Int Health. 2010; 15:1037-1048. [PubMed: 20545921]

LeOra Software. POLO-PC: a user's guide to probit or logit analysis computer program. Berkeley: LeOra Software; 1987. version by

Noireau F, Rojas Cortez M, Monteiro F, Jansen A, Torrico F. Can wild Triatoma infestans foci in Bolivia jeopardize Chagas disease control efforts? Trends Parasitol. 2005; 21:1-12. [PubMed: 15639731]

Paulone I, Chuit R, Perez A, Wisnivesky-Colli C, Segura EL. Field research on an epidemiological surveillance alternative of Chagas' disease transmission: the primary health care (PHC) strategy in rural areas. Rev Arg Microbiol. 1988; 20:103-105.

Piccinali RV, Canale DM, Sandoval AE, Cardinal MV, Jensen O, Kitron U, Gürtler RE. Triatoma infestans bugs in southern Patagonia, Argentina. Emerg Infect Dis. 2010; 16:887-889. [PubMed: 20409398]

Picollo MI, Vassena C, Orihuela PS, Barrios S, Zaidemberg M, Zerba E. High resistance to pyrethroid insecticides associated with ineffective field treatments in Triatoma infestans (Hemiptera: Reduviidae) from northern Argentina. J Med Entomol. 2005; 42:637-642. [PubMed: 16119553]

Robertson, J.; Preisler, H. Pesticide bioassays with arthropods. Boca Raton: CRC; 1992.

Roca Acevedo G, Cueto GM, Germano M, Orihuela PS, Cortez MR, Noireau F, Picollo MI, Vassena C. Susceptibility of sylvatic Triatoma infestans from Andeans valleys of Bolivia to deltamethrin and fipronil. J Med Entomol. 2011; 48:828-835. [PubMed: 21845942]

Schmunis GA, Zicker F, Moncayo A. Interruption of Chagas' disease transmission though vector elimination. Lancet. 1996; 348:1171. [PubMed: 8888192]

Schofield CJ, Diotaiuti L, Dujardin JP. The process of domestication in Triatominae. Mem Inst Oswaldo Cruz. 1999; 94:375-378. [PubMed: 10677759]

Segura, EL. El control de la enfermedad de Chagas en la República Argentina. In: Silveira, AC., editor. El control de la enfermedad de Chagas en los países del Cono Sur de América. Historia de 
una iniciativa internacional. 1991/2001. Brazil: Pan American Health Organization. Facultad de Medicina do Triangulo Mineiro, Uberaba; 2002.

StataCorp. Stata Statistical Software: Release 9.0 computer program. College Station: StataCorp.; 2005. version By

Vassena C, Picollo M, Zerba E. Insecticide resistance in Brazilian Triatoma infestans and Venezuelan Rhodnius prolixus. Med Vet Entomol. 2000; 14:51-55. [PubMed: 10759312]

Vassena, C.; Picollo, MI.; Orihuela, PS.; Zerba, E. Desarrollo y manejo de la resistencia a insecticidas. In: Cortez, M Rojas, editor. Triatominos de Bolivia y la enfermedad de Chagas. Bolivia: Ministerio de Salud y Deportes, Programa Nacional de Chagas; 2007.

Wilkinson, CF. Role of mixed-function oxidases in insecticide resistance. In: Georghiou, G.; Saito, T., editors. Pest Resistance to Pesticides. New York: Plenum Press; 1983. p. 191

World Health Organization. Protocolo de evaluación de efecto insecticida sobre triatominos. Acta Toxicol Arg. 1994; 2:29-32.

World Health Organization. Reporte sobre la enfermedad de Chagas. 2007. TDR/SWG/09

Zerba E, Wallace G, Picollo MI, Casabé N, de Licastro SA, Wood E, Hurvitz A, Andrés A. Evaluación de la beta-cipermetrina para el control de Triatoma infestans. Pan Am J Publ Health. 1997; 1:133137. 

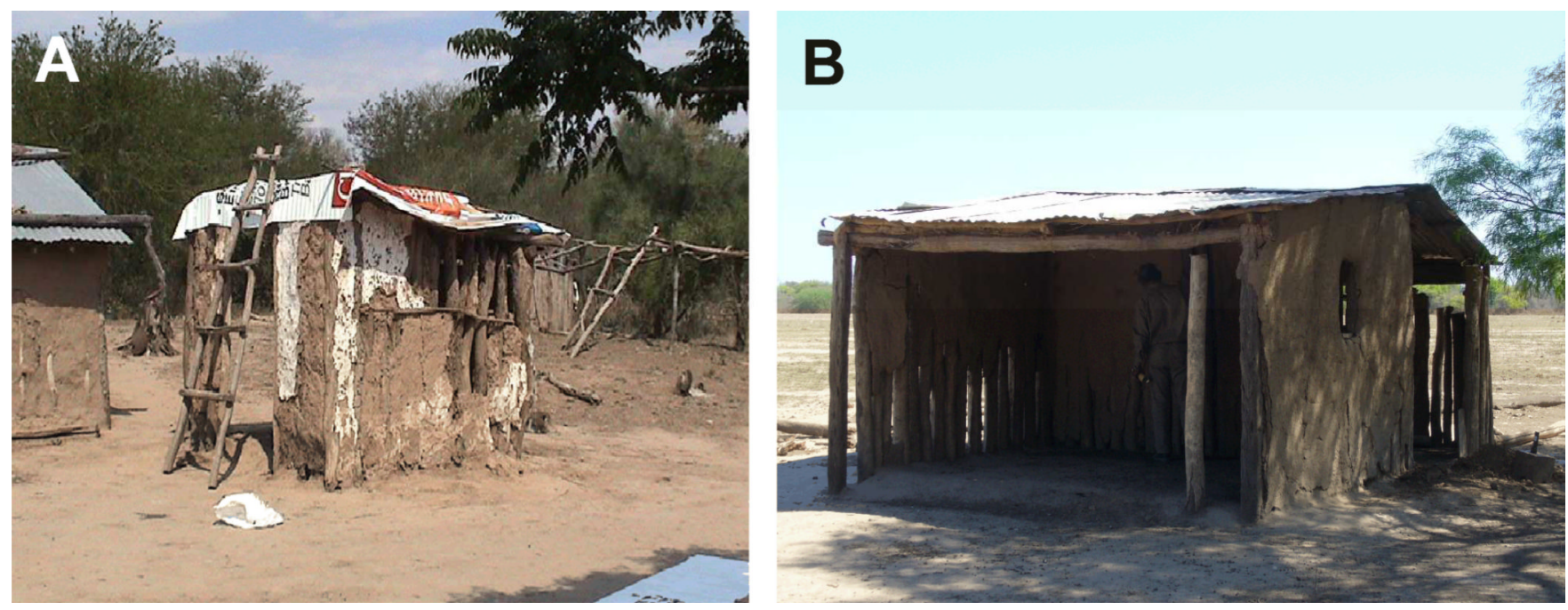

Figure 1.

Peridomestic sites for the residual foci experiment. A) Former house chapel. B) Abandoned hut. 
A

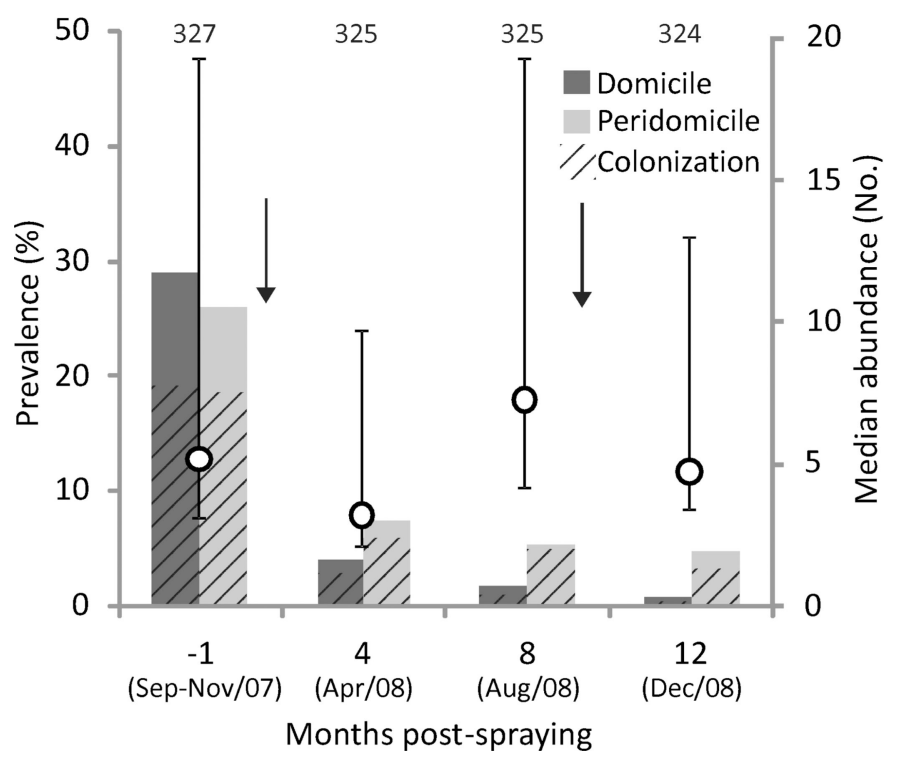

B

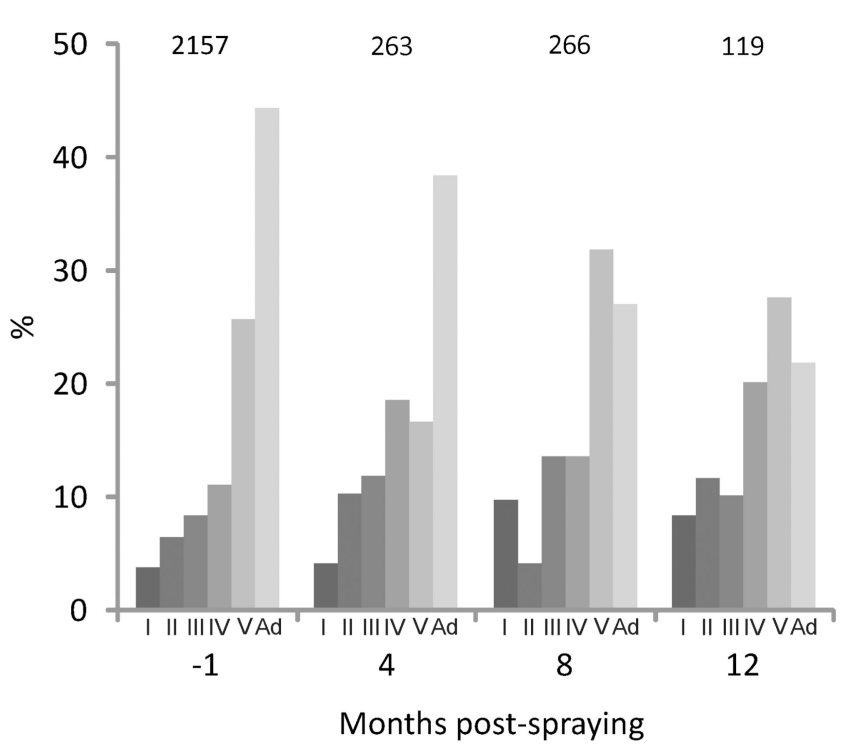

Figure 2.

Infestation and colonization by $T$. infestans before and after community-wide spraying with pyrethroid insecticides in Pampa del Indio. A) Domestic and peridomestic infestation (solid bars) and colonization (lined bars), and median bug abundance (by TMC) in infested sites (symbols). Whiskers represent interquartile range of bug abundance. Numbers above bars indicate number of houses inspected. Arrows represent the initial insecticide spray and the selective sprays. B) Stage structure of timed-manual collections of $T$. infestans before and after insecticide spraying. "I"-"V" denote first- to fifth-instar nymphs; "Ad" denotes adults. Numbers above bars indicate total bug collections. 


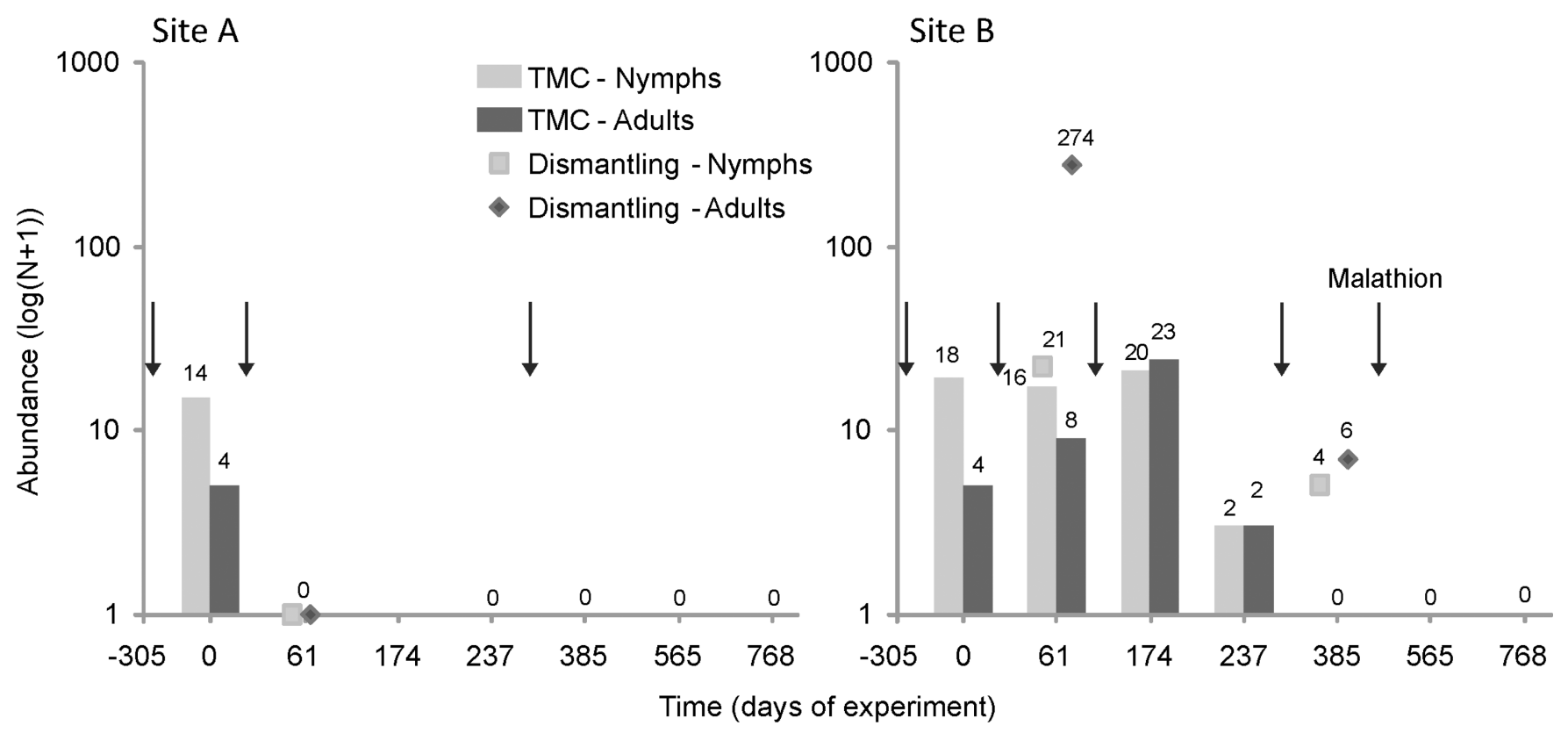

Figure 3.

Residual foci experiment: collections of $T$. infestans by timed-manual searches (TMC) according to stage (bars), by partial dismantling of walls (symbols), and insecticide sprays (arrows) in sites A and B. Last insecticide spray of site B used malathion; all others used pyrethroids. Numbers above bars indicate the number of collected bugs of the respective stage. 


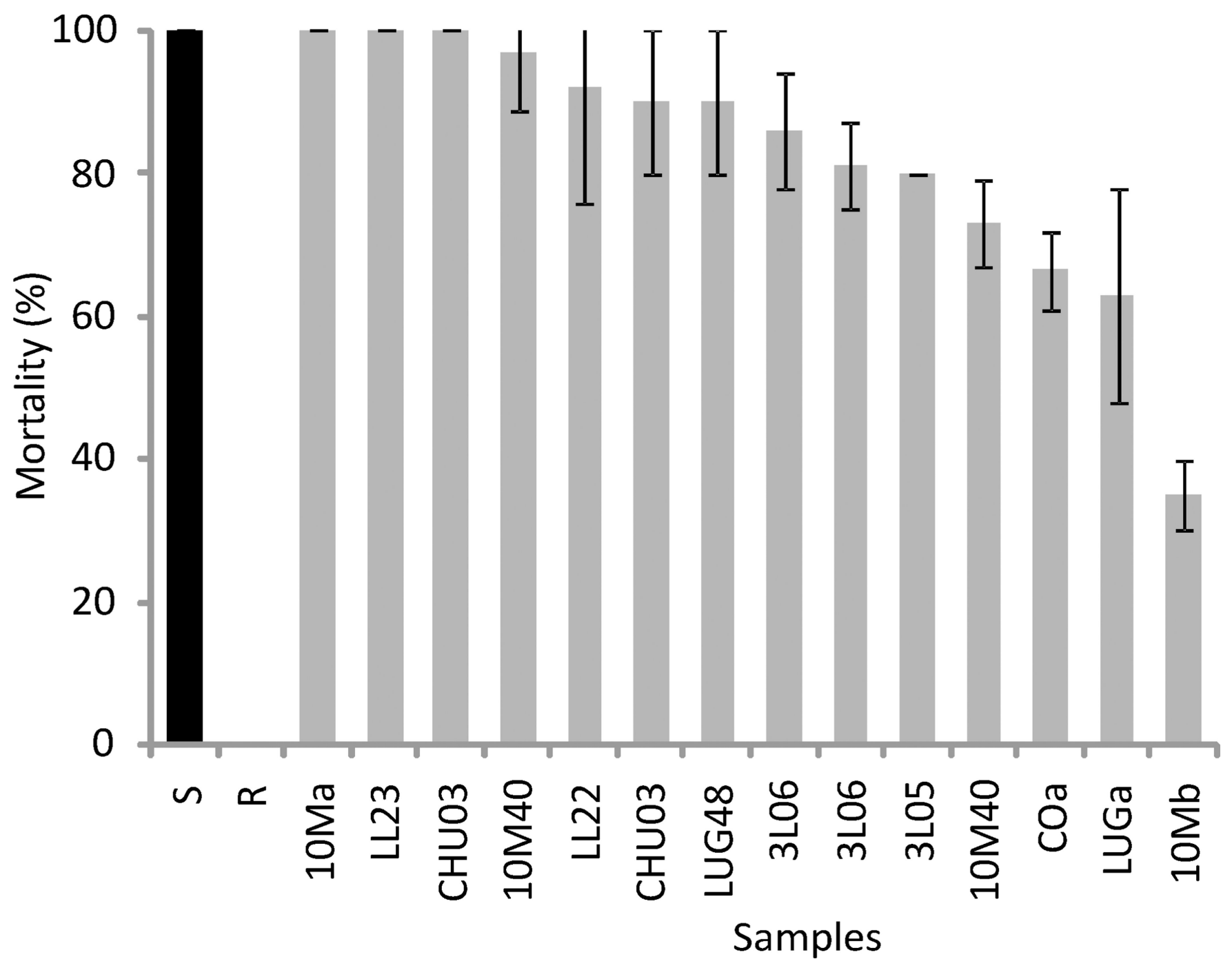

Figure 4.

Mortality of $T$. infestans populations from Pampa del Indio exposed to diagnostic doses (DL 99 ) of deltamethrin. S, susceptible control colony; R, resistant control colony. Whiskers indicate $95 \%$ confidence intervals. 


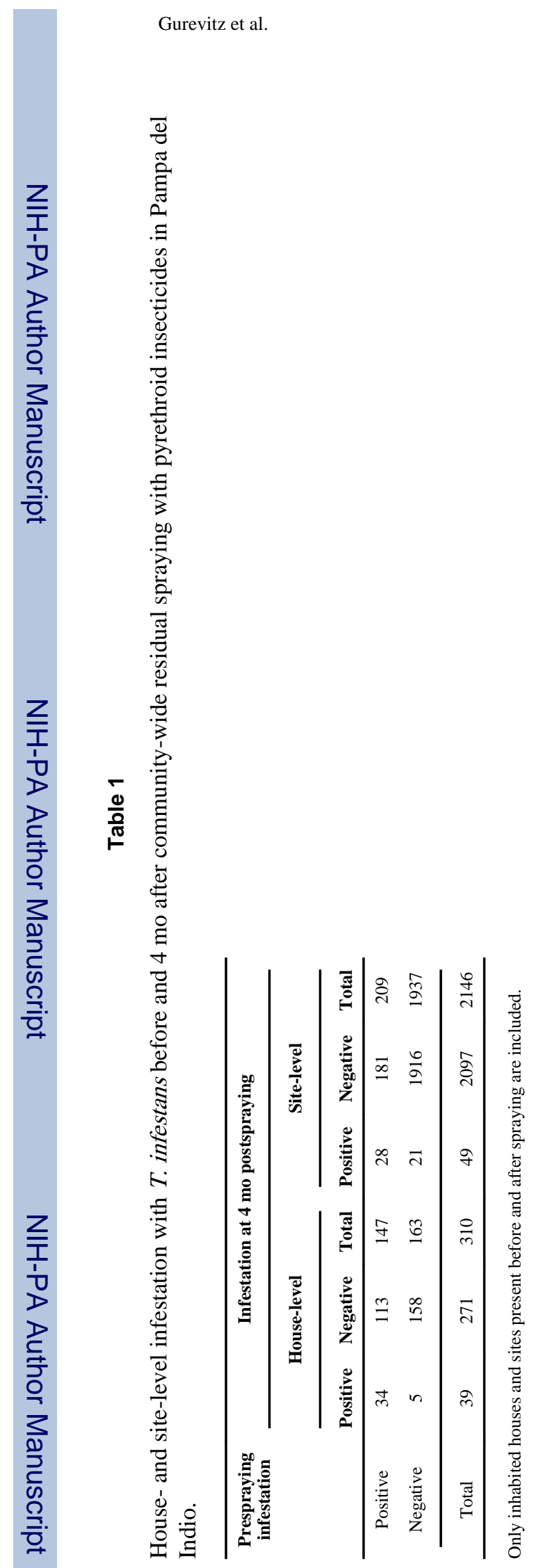

J Med Entomol. Author manuscript; available in PMC 2013 September 03. 